\section{CLINICAL NEPHROLOGY}

Twenty percent of patients with juvenil diabetes mellitus (JDM) will develop renal failure within 30 years. The interval between the first clinical signs of nephropathy and terminal renal failure averages 3 years. To find early predictors of diabetic nephropathy, renal functional studies are being carried out in the 250 children followed in the diabetic section of this hospital. Glomerular filtration rate (GFR) and the clearance of Beta-2-microglobulin and albumin are determined. Results are presently available from 80 children and show that CFR is igcreased already shortly after the onset of JDM ( 149 $\pm 20 \mathrm{ml} / 1.73 \mathrm{~m} / \mathrm{min}$ as compared to $110 \pm 12$ in controls). GFR remains on a high level during the first 10 years after the onset. $10-15$ years after the onset, GFR is no longer sign. different from that in controls. 15 years after the onset, subnormal GFR values are recorded in some patients. $0-2$ years after the onset there is a positive correlation between GFR on one hand and average blood sugar and $\mathrm{HbA} C$ on the other hand. 2-6 years after the onset there is no correlation between GFR and HbA, C. $6-10$ years after the onset there is a negative correlation between GFR and HbA $\mathrm{C}$. Fractional excretion of Beta-2-microglobulin is normal in all patients suggesting that the changes in diabetic nephropathy are primarily glomerular. The different correlations between GFP and metabolic control recorded early after the onset and during the later course of the disease suggest that the changes in GFR in JDM are due both to functional adaptation to the altered metabolism and to progressive structural changes.

32 RENAL FUNCTION IN CYSTIC FIBROSIS. Berz, U., Kusoffsky, E.O., Kallner, A. and Strandvi $k_{1}, B$. Denartment of Pediatrics, Karolinska Institute, Huddinge University Hospital, Stockholr., Sweden.

The main diagnostic criteria in crstic fibrosis (CF) is an elevated concentration of sodium chloride in sweat. As the kidney is the main requlator of sodium homeostasis it was of special interest to study renal function in $C F$.

Sixteen patients with $\mathrm{CF}, 5-19$ years of are, were studied. Oral and intravenous (iv) sodium load tests were nerformed including clearances of inulin and PAH. Standardized clearance technique was used.

Glomerular filtration rate (GFR) and filtration fraction (FF) were increased compared to controls. Renal plasma flow was normal. Basal urinary sodium excretion as well as renal responses to oral and iv sodium loads were low indicating an increased renal sodium reabsorption. Dilutinf capacity was decreased because of a low distal sodium delivery indicating an increased proximal sodium reabsorption.

Ten CF-children were treated with Intralipid ${ }^{R}$ at repular intervals for one year. The GFR decreased to normal values and the urinary elimination rate of an oral sodium load was still low but increased sipnificantly compared to that before treatment.

The increased GFR and proximal sodium reabsorntion found in CF might be due to a chanpe in fatty acid composition of the cell membrane and/or a disturbance of the prostaplandin metabolism. ACUTE GLOMERULONEPHRITIS (AGN). Mote, H.F., Feiman, R, Seracho, P. and Gordillo, P.G. Hospital Infantil de México. Mexico City. Mexico.

Inability to increase fractional excretion of filtered sodium (FENa) after sodium loading has been demonstrated in

experimental AGN. Adult patients with AGN show FENa below 1.0

Since early changes in renal sodium handling in children with AGN are lacking, we studied 41 patients with post-streptococcal AGN ( 3 to 12 yrs. old). They all had hypertension with no previous treatment. The following urine-to-plasma ratio (UP) Indices were studied: urea, osmolality, sodium, creatinine $(\mathrm{Cr})$, and FENa. Patients were distributed into 3 groups: (1): $1-5$ days of evolution, 18 cases: (II): 6 to 10 days, 15 cases; (1II): 11 to 15 days, 8 cases.

FENa in I was below $1.0(\bar{x}=0.29+0.39)$; most cases of 11 and 111 were obove $1.0(\bar{x}=1.0+0.7$ and $1.6+1.1$ respect ively: $p<0.01$ between $I$ and 11 and 1 and 111$)$. UPC $\bar{r}$ and UCr were: 1) $245+170$ and $236+144 ;$ 11) $61+37$ and $67+50 ; 111) 69+$ 70 and $62 \pm 54$ ( $<<0.01$ between 1 and 11 and 1 and 111 ). No difference of age, sex and the other indices between the 3 groups were found.

Our results show progresive increase of $\mathrm{FENa}$ in relation with time of evolution, depending on UCr changes. Early higher values of UCr suggest a temporary compensatory increase of glomerular filtration rate, probably secondary to hypervolemia.

Hypervolemia might be produced by initial hemodynamic changes

resulting from glomerular injury.
CREATININE CLEARANCE IN UNLERWEIGHT CHILLREN'

34 Mehta K.P.; Patkar L. A.; Babar S.T.

B. Jerbai Wadia Hospital for Children, Bombay, India.

Estimation of endogenous creatinine clearance ( $\mathrm{Cr} . \mathrm{Cl}$.) was done in 139 apparently healthy Indian children ( 94 boys and 45 girls) between $4-12$ years age belonging to poor socio economic class. The mean $\mathrm{Cr}$. Cl. was $56.84 \mathrm{ml} / \mathrm{min} / 1.73 \mathrm{M}$ (59.54 in boys and 53.12 in girls) which was lower than reported from West $\left(127 \mathrm{ml} / \mathrm{min} / 1.73 \mathrm{Nl}^{2}\right.$ by Barnett et al $)$. Analysing the data it was noted that $\mathrm{Cr} . \mathrm{Cl}$. was influenced by weight and not aye. There was statistically significant difference in $\mathrm{Cr} . \mathrm{Cl}$. values of children below 10 th percentile by weight when compared with those above 10th percentile by I. CN.R. (Indian Council of Medical Research) Standard for weight. Mean $\mathrm{Cr} . \mathrm{Cl}$. for girls and boys below 10 th percentile were 36.9 and $45.3 \mathrm{ml} / \mathrm{min} / 1.73 \mathrm{~N}$. while for those above 25 th percentile were 54.5 and $61.8 \mathrm{ml} /$ $\mathrm{min} / 1.73 \mathrm{Ni}^{2}$ respectively. Low $\mathrm{Cr} . \mathrm{Cl}$. in underweight children was due to low urinary creatinine excretion due to poor muscle mass $(25.8 \mathrm{mg} / \mathrm{dl}$ and $55.6 \mathrm{mg} / \mathrm{dl}$ in children belonging to 10 th and 25 th percentile by weight respectively. The serum creatinine levels and urine volume per minute did not differ according to age, sex or weight.

35 ALBUMINURIA IN DIABETIC CHILDREN . Huttunen, NP.,Käär, M-I., Akerblom, H.K.Depto of Paediatr., University of oulu, oulu, Finland.

Silgth albuminuria has been induced by exercise in young adults with juvenilemonset insulin-dependent diabetes mellitus of short duration. We studied the influence of exercise on albuminuria in 46 diabetic and 38 healthy children using radiolmmunoassay. The age of the children ranged from 9 to 18 years. The children worked on a bicycle ergometer for 16 minutes with increasing work load. In both groups, the pulse rate at the end of the exeroise was $185 \pm 6 / \mathrm{min}$. At reat the geometric mean of the albumin excretion rate of healthy children was $4.7 \mu \mathrm{g} / \mathrm{min} / \mathrm{m}^{2}$, that of digbetica with a duration 1 ess than 5 years $6.0 \mu \mathrm{g} / \mathrm{min} / \mathrm{m}^{2}$ and with a duration more than 5 years $9.1 \mu \mathrm{g} / \mathrm{min} / \mathrm{m}^{2}$. During exercise, the albumin excretion was $8.5,10.0$ and 19.5 $\mathrm{\mu g} / \mathrm{min} / \mathrm{m}^{2}$, respectively. During rest and exercise the albumin excretion was significantly increased in chlldren with diabetes for more than 5 years. At rest the extent of albuminuria correlated with blood HbA1 concentration.During exercise there was a corrolation between albuminuria and blood pressure rise in diabetio but not in healthy children. It is concluded that early algens of diabetio nephropathy can be detected with special techniques as soon as in childhood and the appearance of albuminuria is dependent on the metabolic balance of diabetes.

36

STANDING CREATININE CLEARANCE IN CHILDREN WITH LATENT GLOMERULONEPHRITIS

Tateishi,S., Kyoto City Hospital, Kyoto, Japan.

In order to evaluate the usefulness of postural loading in estimating the degree of latent glomerular lesion, creatinine clearance(C.cr.) was measured in supine and upright position in 3 groups of renal patients whose standard C.cr. was within normal limits.

Group A consisted of 19 children with minimal or no glomerular lesion; and Group B included 33 children with histologically proven glomerulonephritis. The latter group was further divided into B-1(mild) and B-2(moderate), according to histologic finding

As shown in the table below, C.cr. decreased significantly by postural loading in Group $B$, particularly in Group B-2, but not in Group A.

\begin{tabular}{l|c|r|r|r}
\hline \multirow{2}{*}{ Group } & No. of & \multicolumn{2}{|c|}{ C.cr. $\left(\mathrm{ml} / \mathrm{m} / 1.48 \mathrm{~m}^{2}\right)$} & \multirow{2}{*}{ \% Decrease } \\
\cline { 3 - 4 } & cases & \multicolumn{1}{|c|}{ Supine } & Upright & \\
\hline A & 19 & $116.9 \pm 26.8$ & $101.5 \pm 27.7$ & $13.5 \pm 9.1$ \\
B & 33 & $99.8 \pm 19.0$ & $73.4 \pm 22.9$ & $27.6 \pm 13.0$ \\
B-1 & 21 & $108.2 \pm 16.5$ & $84.2 \pm 18.6$ & $22.5 \pm 9.6$ \\
B-? & 12 & $85.0 \pm 13.0$ & $54.4 \pm 16.5$ & $36.5 \pm 13.2$ \\
\hline
\end{tabular}

It was concluded that the measurement of c.cr. in standing position might be useful in estimating the degree and activity of latent glomerular lesion in childhood glomerulonephritis. 